\title{
ENGINEERING DEVELOPMENT OF COAL-FIRED HIGH-PERFORMANCE POWER SYSTEMS
}

DE-AC22-95PC95143--20

TECHNICAL PROGRESS REPORT NO. 20

APRIL THROUGH JUNE 2000

\author{
Prepared for \\ Department of Energy \\ Federal Energy Technology Center \\ Pittsburgh, Pennsylvania
}

AUGUST 2000 
"This report was prepared as an account of work sponsored by an agency of the United States Government. Neither the United States Government nor any agency thereof, nor any of their employees, makes any warranty, express or implied, or assumes any legal liability or responsibility for the accuracy, completeness, or usefulness of any information, apparatus, product, or process disclosed, or represents that its use would not infringe privately owned rights. Reference herein to any specific commercial product, process, or service by trade name, trademark, manufacturer, or otherwise does not necessarily constitute or imply its endorsement, recommendation, or favoring by the United States Government or any agency thereof. The views and opinions of authors expressed herein do not necessarily state or reflect those of the United States Government or any agency thereof." 


\section{ABSTRACT}

A High Performance Power System (HIPPS) is being developed. This system is a coal-fired, combined cycle plant with indirect heating of gas turbine air. Foster Wheeler Development Corporation and a team consisting of Foster Wheeler Energy Corporation, Bechtel Corporation, University of Tennessee Space Institute and Westinghouse Electric Corporation are developing this system. In Phase 1 of the project, a conceptual design of a commercial plant was developed. Technical and economic analyses indicated that the plant would meet the goals of the project which include a 47 percent efficiency (HHV) and a 10 percent lower cost of electricity than an equivalent size PC plant.

The concept uses a pyrolysis process to convert coal into fuel gas and char. The char is fired in a High Temperature Advanced Furnace (HITAF). The HITAF is a pulverized fuel-fired boiler/air heater where steam is generated and gas turbine air is indirectly heated. The fuel gas generated in the pyrolyzer is then used to heat the gas turbine air further before it enters the gas turbine.

The project is currently in Phase 2 which includes engineering analysis, laboratory testing and pilot plant testing. Research and development is being done on the HIPPS systems that are not commercial or being developed on other projects. Pilot plant testing of the pyrolyzer subsystem and the char combustion subsystem are being done separately, and after each experimental program has been completed, a larger scale pyrolyzer will be tested at the Power Systems Development Facility (PSDF) in Wilsonville, AL. The facility is equipped with a gas turbine and a topping combustor, and as such, will provide an opportunity to evaluate integrated pyrolyzer and turbine operation.

This report addresses the areas of technical progress for this quarter. The detailed design of the major process equipment to be installed at the pilot plant in Livingston, New Jersey has been completed. The existing bubbling bed plant is to be modified to a circulating fluidized bed (CFB) pyrolyzer. Preliminary construction work of the new CFB pyrolyzer has started in this quarter. In order to prepare the CETF for the HIPPS char combustion test program, the construction work of a new indirect char feeding system to be used for the wall-fired char combustion tests was completed during this quarter. 


\section{TABLE OF CONTENTS}

PAGE

NO.

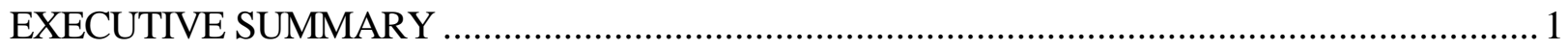

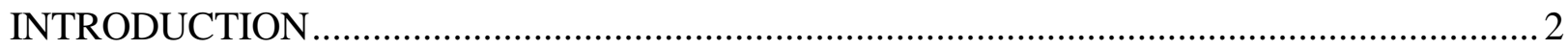

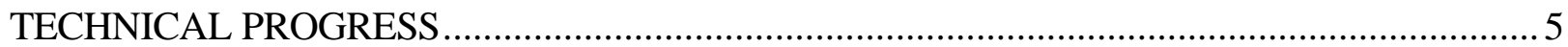

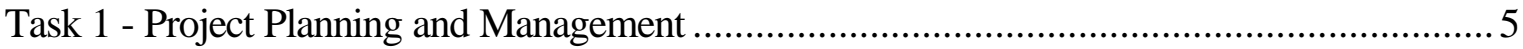

Task 2 - Engineering Research and Development ...................................................... 5

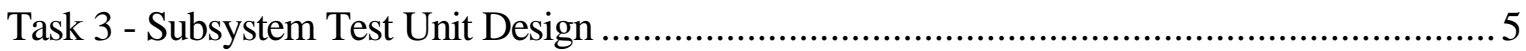

Subtask 3.1 - Livingston Pilot Plant Design......................................................... 5

Subtask 3.2 - Char Combustion System Test Design.............................................. 6

Task 4 - Subsystem Test Unit Construction ................................................................ 9

Subtask 4.1 - Livingston Pilot Plant Construction........................................................ 9

Subtask 4.2 - Char Combustion System Construction ........................................... 10

Task 5 - Subsystem Test Unit Testing ........................................................................... 10 


\section{$\underline{\text { LIST OF FIGURES \& TABLES }}$}

FIGURE

PAGE

NO.

NO.

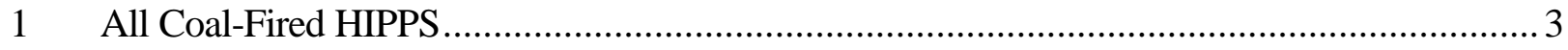

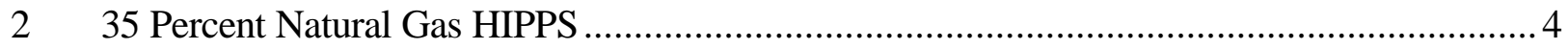

3 Simplified HIPPS Repowering Process Flow Diagram .................................................... 4

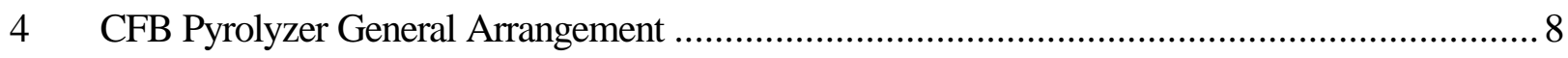

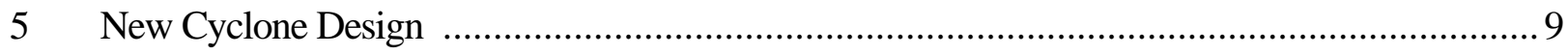

6 Overall CFB Pyrolyzer System Construction and Testing Schedule.................................... 11

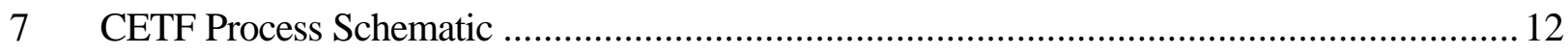

8 New Loss-in-Weight and Pneumatic Conveying Feed System ......................................... 13

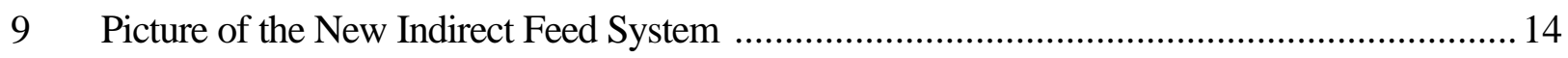

10 Picture of the New Loss-in-Weight Feed System ................................................... 15

TABLE

PAGE

NO.

NO.

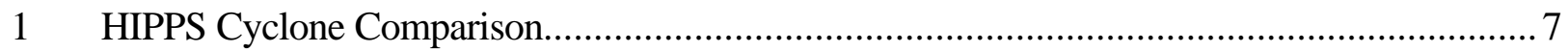




\section{EXECUTIVE SUMMARY}

The High Performance Power System is a coal-fired, combined cycle power generating system that will have an efficiency of greater than 47 percent (HHV) with NOx and SOx less than $0.025 \mathrm{Kg} / \mathrm{GJ}(0.06$ $\mathrm{lb} / \mathrm{MMBtu}$ ). This performance is achieved by combining a coal pyrolysis process with a High Temperature Advanced Furnace (HITAF). The pyrolysis process consists of a pressurized fluidized bed reactor which is operated at about $926^{\circ} \mathrm{C}\left(1700^{\circ} \mathrm{F}\right)$ at substoichiometric conditions. This process converts the coal into a low-Btu fuel gas and char. These products are then separated.

The char is fired in the HITAF where heat is transferred to the gas turbine compressed air and to the steam cycle. The HITAF is fired at atmospheric pressure with pulverized fuel burners. The combustion air is from the gas turbine exhaust stream. The fuel gas from the pyrolysis process is fired in a Multi-Annular Swirl Burner (MASB) where it further heats the gas turbine air leaving the HITAF. This type of system results in very high efficiency with coal as the only fuel.

We are currently in Phase 2 of the project. In Phase 1, a conceptual plant design was developed and analyzed both technically and economically. The design was found to meet the project goals. The purpose of the Phase 2 work is to develop the information needed to design a prototype/commercial plant. Phase 3 of the overall HIPPS contract has been deleted. In addition to engineering analysis and laboratory testing, the subsystems that are not commercial or being developed on other projects will be tested at pilot plant scale. The FWDC Second-Generation PFB pilot plant in Livingston, NJ, has been modified to test the pyrolyzer subsystem. The FWDC Combustion and Environmental Test Facility (CETF) in Dansville, NY, has been modified to test the char combustion system. Integrated operation of a larger scale pyrolyzer and a commercial gas turbine are planned for the PSDF in Wilsonville, AL.

The detailed design of the major process equipment to be installed at the pilot plant in Livingston, New Jersey has been completed. The existing bubbling bed plant is to be modified to a circulating fluidized bed (CFB) pyrolyzer. Preliminary construction work of the new CFB pyrolyzer has started in this quarter. In order to prepare the CETF for the HIPPS char combustion test program, the construction work of a new indirect char feeding system to be used for the wall-fired char combustion tests was completed during this quarter. 


\section{INTRODUCTION}

In Phase 1 of the project, a conceptual design of a coal-fired high performance power system was developed, and small scale R\&D was done in critical areas of the design. The current Phase of the project includes development through the pilot plant stage.

Foster Wheeler Development Corporation (FWDC) is leading a team of companies in this effort. These companies are:

- Foster Wheeler Energy Corporation (FWEC)

- Bechtel Corporation

- Westinghouse Electric Corporation

The power generating system being developed in this project will be an improvement over current coal-fired systems. Goals have been identified that relate to the efficiency, emissions, costs and general operation of the system. These goals are:

- Total station efficiency of at least 47 percent on a higher heating value basis.

- Emissions:

$$
\begin{aligned}
& \text { NOx }<0.06 \mathrm{lb} / \mathrm{MMBtu} \\
& \mathrm{SOx}<0.06 \mathrm{lb} / \mathrm{MMBtu} \\
& \text { Particulates }<0.003 \mathrm{lb} / \mathrm{MMBtu}
\end{aligned}
$$

- All solid wastes must be benign with regard to disposal.

- Over 95 percent of the total heat input is ultimately from coal, with initial systems capable of using coal for at least 65 percent of the heat input.

The base case arrangement of the HIPPS cycle is shown in Figure 1. It is a combined cycle plant. This arrangement is referred to as the All Coal HIPPS because it does not require any other fuels for normal operation. A fluidized bed, air blown pyrolyzer converts coal into fuel gas and char. The char is fired in a high temperature advanced furnace (HITAF) which heats both air for a gas turbine and steam for a steam turbine. The air is heated up to $760^{\circ} \mathrm{C}\left(1400^{\circ} \mathrm{F}\right)$ in the HITAF, and the tube banks for heating the air are constructed of alloy tubes. The fuel gas from the pyrolyzer goes to a topping combustor where it is used to raise the air entering the gas turbine to $1288^{\circ} \mathrm{C}\left(2350^{\circ} \mathrm{F}\right)$. In addition to the HITAF, steam duty is achieved with a heat recovery steam generator (HRSG) in the gas turbine exhaust stream and economizers in the HITAF flue gas exhaust stream. 


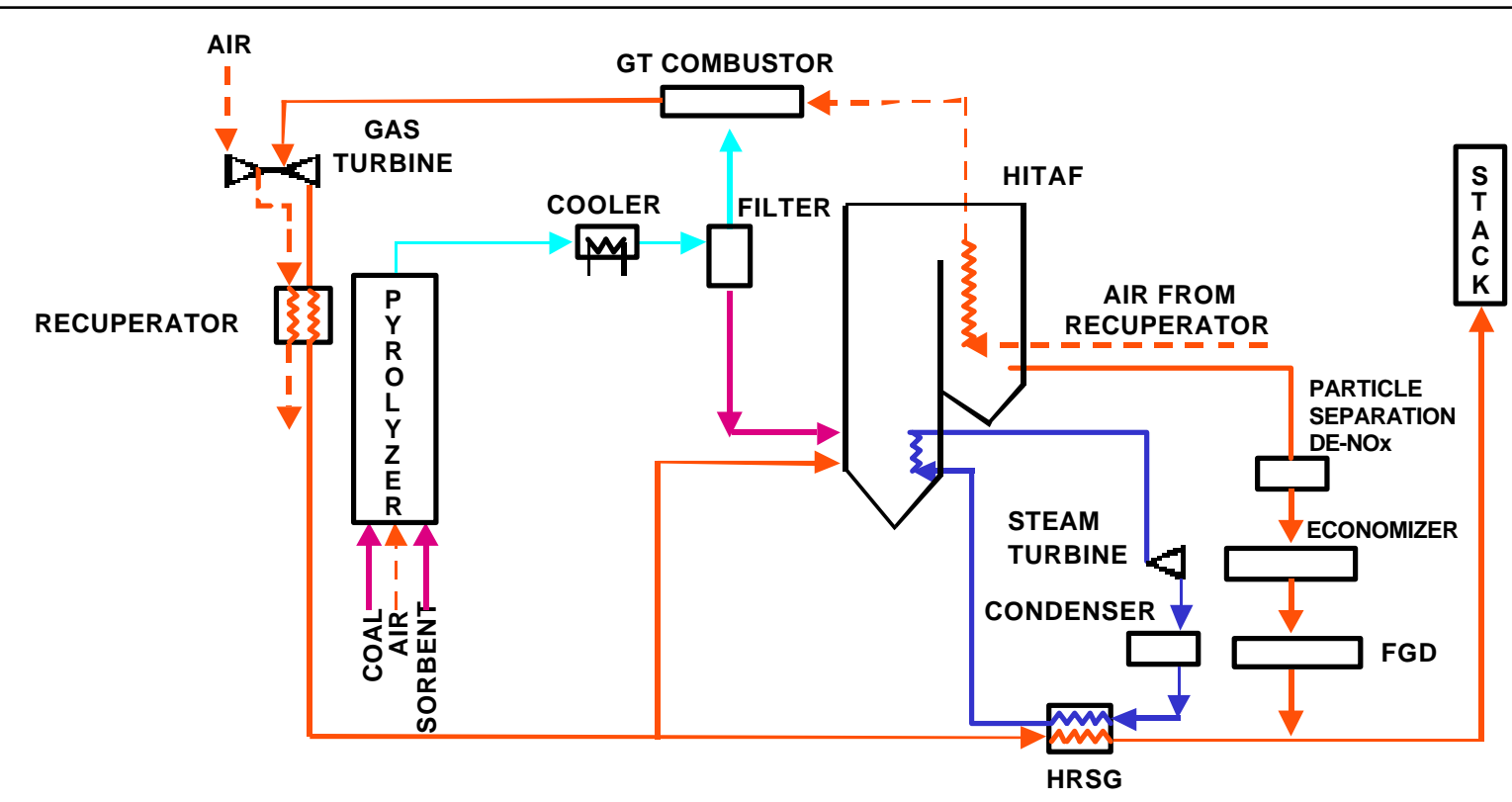

Figure 1 All Coal Fired HIPPS

An alternative HIPPS cycle is shown in Figure 2. This arrangement uses a ceramic air heater to heat the air to temperatures above what can be achieved with alloy tubes. This arrangement is referred to as the 35 percent natural gas HIPPS, and a schematic is shown in Figure 2. A pyrolyzer is used as in the base case HIPPS, but the fuel gas generated is fired upstream of the ceramic air heater instead of in the topping combustor. Gas turbine air is heated to $760^{\circ} \mathrm{C}\left(1400^{\circ} \mathrm{F}\right)$ in alloy tubes the same as in the All Coal HIPPS. This air then goes to the ceramic air heater where it is heated further before going to the topping combustor. The temperature of the air leaving the ceramic air heater will depend on technological developments in that component. An air exit temperature of $982^{\circ} \mathrm{C}\left(1800^{\circ} \mathrm{F}\right)$ will result in 35 percent of the heat input from natural gas.

A simplified version of the HIPPS arrangement can be applied to existing boilers. Figure 3 outlines the potential application of the HIPPS technology for repowering existing pulverized coal fired plants. In the repowering application, the gas turbine exhaust stream provides the oxidant for co-fired combustion of char and coal. The existing boiler and steam turbine infrastructure remain intact. The pyrolyzer, ceramic barrier filter, gas turbine, and gas turbine combustor are integrated with the existing boiler to improve overall plant efficiency and increase generating capacity. 


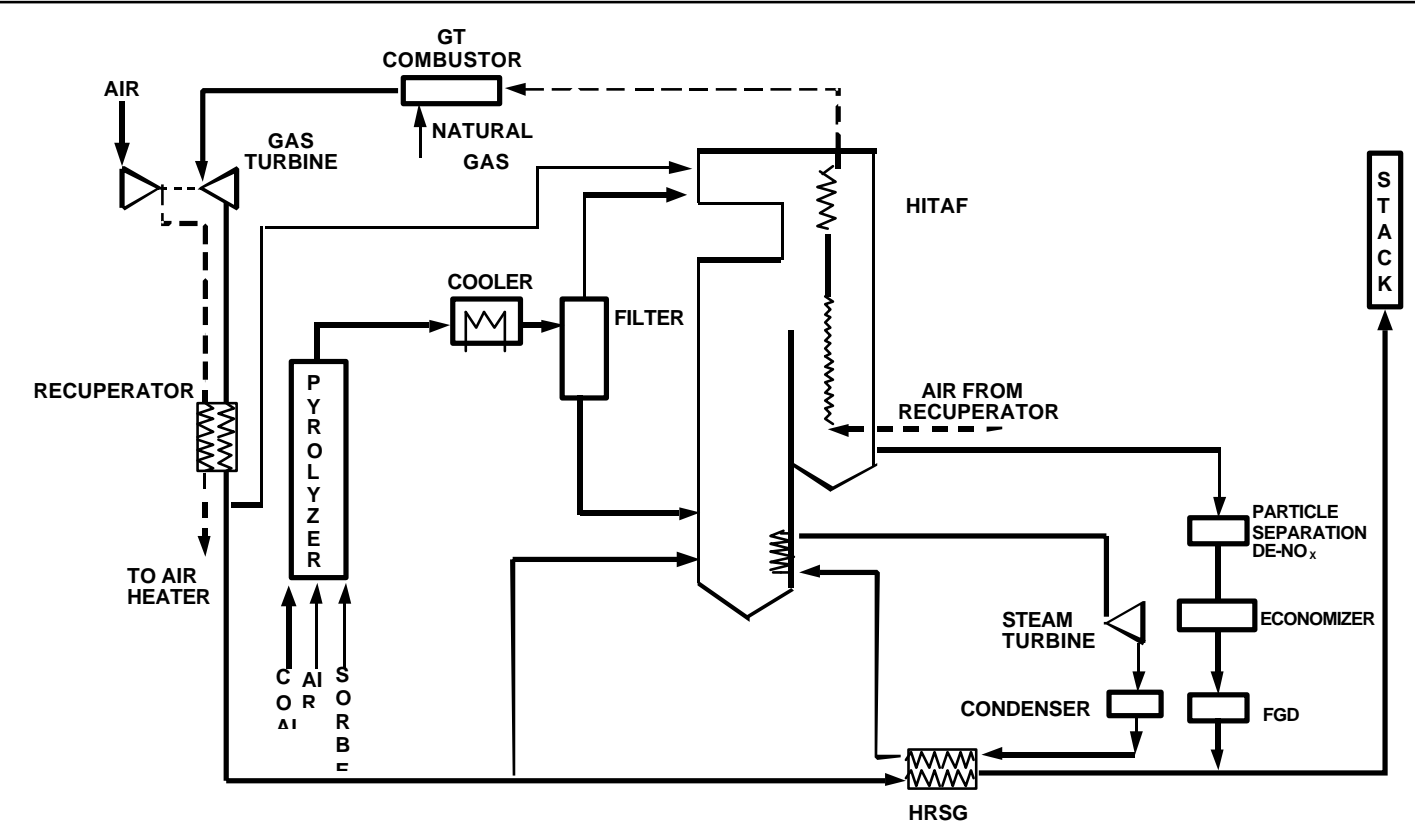

Figure 2 35-Percent Natural Gas

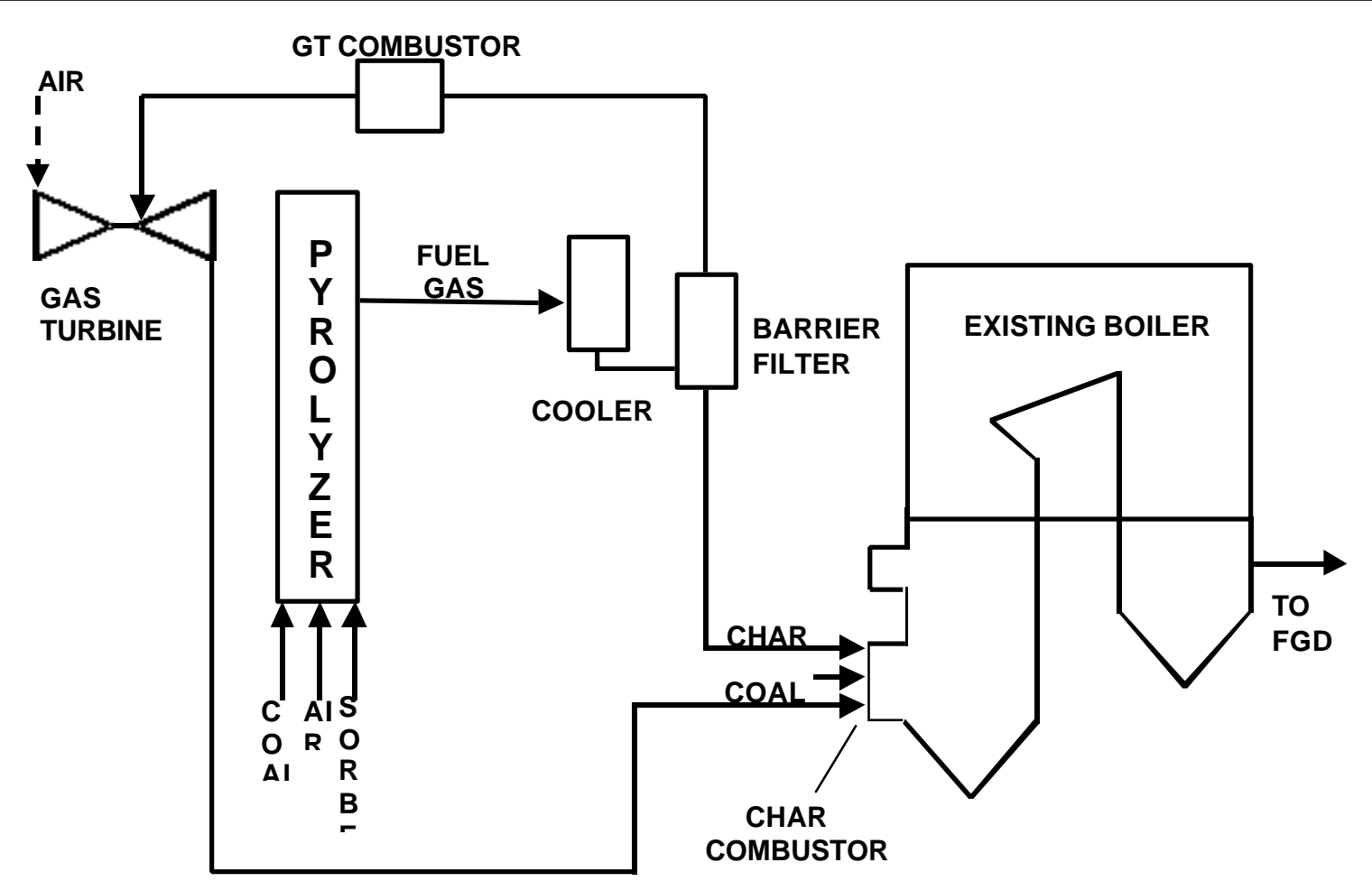

Figure 3 Simplified HIPPS Repowering Process Flow Diagram 


\section{TECHNICAL PROGRESS}

\section{Task 1 - Project Planning and Management}

Work is progressing according to the process plan.

\section{Task 2 - Engineering Research and Development}

No engineering $R \& D$ work was performed during this quarter.

\section{Task 3 - Subsystem Test Unit Design}

\section{Subtask - 3.1 Livingston Pilot Plant Design}

In fiscal year 2000, HIPPS pyrolyzer testing at FWDC's PFB Pilot Plant Facility in Livingston, NJ, is scheduled to take place. The bubbling bed pyrolyzer arrangement previously tested is to be retrofitted to operate as a circulating fluidized bed. The purpose of the test program is to demonstrate stable hydrodynamic performance and steady fuel gas composition. The circulating bed pyrolyzer is easier to scale up to commercial sized applications than the bubbling bed system, and, as such, has broader market potential. During this report period, several areas of the existing CFB pyrolyzer design proposed in 1996 have been reviewed and modified. Figure 4 shows the general arrangement of the new CFB pyrolyzer.

Cyclone: The purpose of this study was to compare the existing cyclone fabricated in 1997 with other proposed designs for high-pressure CFB operation. The viability of several different cyclone designs for the HIPPS unit operating in CFB fluidization mode was performed. Table 1 summarizes the dimensions of the various cyclones tested. Five different cases were run and evaluated with the PSRI fluidized bed systems cyclone design spread sheet program for char and gas of $23 \mathrm{lbm} / \mathrm{ft}^{3}$ and $0.2596 \mathrm{lbm} / \mathrm{ft}^{3}$ respectively. The pressure was 206 PSIG and temperature was $1650 \mathrm{EF}$. The analysis assumes that the circulating mass is only char.

Out of the five HIPPS designs listed in Table 1, all four listed HIPPS Options will have greater efficiency and lower pressure drop than the existing HIPPS design cyclone. In cyclones, barrel length is a critical parameter when designing for collection efficiency. If a barrel is too short, the vortex will swing to the walls of the cone and draw solids out decreasing the efficiency. There are a few aspects of the PSRI cyclone design program output worth noting. It should be understood that the reported barrel length (recommended) of the cyclone is a calculated number based on the calculated minimum vortex length $(\mathrm{L})$, other geometrical input and then adds 3 inches. Also, the pressure drop values reported are a sum of all the losses associated with the flow traveling through the cyclone. These are dominated by the loss due to solids acceleration from the riser through the inlet of the cyclone. The horizontal pipe, which carries the flow from the riser to the cyclone inlet, is, for all intensive purposes, ignored as an intermediary step. Therefore, the value is considered conservative as the solids acceleration losses are based on acceleration from the 7" riser and assumed to be initially $15 \mathrm{ft} / \mathrm{sec}$. Actual values are expected to be less. The reported values, however, may adequately predict pressure drop from freeboard to cyclone outlet. 
In conclusion, the 1996 HIPPS cyclone design is believed to be a design that can be improved upon. From discussions with PSRI, we are now aware that the 1996 design has an undersized barrel length and undersized inlet area. Option \#4 in Table 1, as shown in Figure 5, is therefore recommended and will be used since it has a lower pressure drop and higher efficiency than the 1996 design.

Fuel Feed System: Two different fuel feed configurations, bottom feed with upward shooting jet and side pneumatic feed, will be implemented and tested. The bottom feed with upward shooting jet is the original fuel feed system in the bubbling bed pyrolyzer arrangement. For the new size feed arrangement, the fuel will be pneumatically injected into the pyrolyzer at $15^{\circ}$ incline from the vertical. The side feed point will be located 8 feet above the primary air feed point and 6.8 feet above the solids recirculation point.

Trace Metal Probe Design: A trace metal probe would have to be designed and built for use during testing. For trace metal measuring, EPA Method 29 would have to be followed. The trace metal probe design has to satisfy the following condition:

- Isokinetic sampling

- Ceramic lining pipes to eliminate contamination

- Ceramic lining pressure regulator to reduce pressure

- Ceramic fiber filter for solids filtration

- Ceramic lining cooling section to reduce temperature

- Pressure seal design

- $\quad$ EPA Method 29 batch mode chemical analysis

After a product survey, we found that there are many commercial vendors supplying Method 29 sampling equipment, but none of them is able to supply probes that can work at high pressure and high temperature. Both probe design and train operation is difficult and challenging. The most common materials used for trace metal sampling trains are glass, quartz, and other, which is "inert" or not containing these trace elements. It is very difficult to find a pressure regulator built with those materials. After a literature survey, we found one paper by a Finnish company (VTT) mentioned that they have a probe designed and used under a coal gasification condition similar to our test condition. An initial contact with VTT has been established during this quarter. VTT has tailor-made probes for several measurements of heavy metals in a pressurized gasifier. The VTT probe is designed for under $1000^{\circ} \mathrm{F}$ measurement. Based on the initial discussion, VTT in principle is willing to supply principal design and assist in identifying component suppliers for our trace metal probe construction.

\section{Subtask - 3.2 Char Combustion System Test Design}

No design work was performed during this quarter. 


\begin{tabular}{|c|c|c|c|c|c|c|c|}
\hline & & & $\begin{array}{l}\text { HIPPS } \\
1996\end{array}$ & $\begin{array}{l}\text { HIPPS } \\
\text { Option } \\
\# 1\end{array}$ & $\begin{array}{l}\text { HIPPS } \\
\text { Option } \\
\text { \#2 }\end{array}$ & $\begin{array}{l}\text { HIPPS } \\
\text { Option } \\
\# 3\end{array}$ & $\begin{array}{l}\text { HIPPS } \\
\text { Option } \\
\# 4\end{array}$ \\
\hline \begin{tabular}{|l} 
Barrel Diameter \\
\end{tabular} & $\mathrm{Db}$ & in & 8.000 & 10.000 & 10.000 & 8.000 & 8.000 \\
\hline Inlet Width & $\mathrm{W}$ & in & 1.752 & 1.500 & 1.500 & 1.500 & 1.500 \\
\hline Inlet Height & $\mathrm{H}$ & in & 4.000 & 6.000 & 6.000 & 6.000 & 6.000 \\
\hline $\mid$ Vortex Tube (ID) & Dv & in & 3.128 & 3.110 & 3.110 & 3.110 & 3.110 \\
\hline Dipleg Diameter & Ddip & in & 6.000 & 3.830 & 5.760 & 3.830 & 5.760 \\
\hline Vortex Tube Length & LV & in & 2.504 & 6.000 & 6.000 & 6.000 & 6.000 \\
\hline Barrel Length (Design) & $\mathrm{Lb}$ & in & 10.000 & 24.400 & 24.400 & 21.320 & 21.320 \\
\hline \begin{tabular}{|l} 
Barrel Length \\
(Recommended)
\end{tabular} & & & 18.020 & 24.400 & 24.400 & 21.320 & 21.320 \\
\hline Cone Length & LC & in & 3.128 & 9.490 & 6.520 & 6.400 & 3.450 \\
\hline Inlet Type & & in & Tang & Tang & Tang & Tang & Tang \\
\hline \multirow[t]{8}{*}{ Cone Angle } & & deg & 72 & 72 & 72 & 72 & 72 \\
\hline & $\mathrm{H} / \mathrm{Db}$ & & 0.500 & 0.600 & 0.600 & 0.750 & 0.750 \\
\hline & W/Db & & 0.219 & 0.150 & 0.150 & 0.188 & 0.188 \\
\hline & $\mathrm{Dv} / \mathrm{Db}$ & & 0.391 & 0.311 & 0.311 & 0.389 & 0.389 \\
\hline & $\begin{array}{c}\text { Ddip/ } \\
\text { Db }\end{array}$ & & 0.750 & 0.383 & 0.576 & 0.479 & 0.720 \\
\hline & $\mathrm{Lv} / \mathrm{Db}$ & & 0.313 & 0.600 & 0.600 & 0.750 & 0.750 \\
\hline & Lb/Db & & 1.250 & 2.440 & 2.440 & 2.665 & 2.665 \\
\hline & Lc/Db & & 0.391 & 0.949 & 0.652 & 0.800 & 0.431 \\
\hline \begin{tabular}{|l|} 
Pressure Drop \\
\end{tabular} & & in $\mathrm{H} 2 \mathrm{O}$ & $\overline{c 162}$ & 97 & 97 & 96 & 96 \\
\hline Overall Collection Eff. & & & $\begin{array}{c}99.969 \\
7\end{array}$ & 99.9701 & 99.9701 & 99.9701 & 99.9701 \\
\hline
\end{tabular}

Table 1 HIPPS Cyclone Comparison 


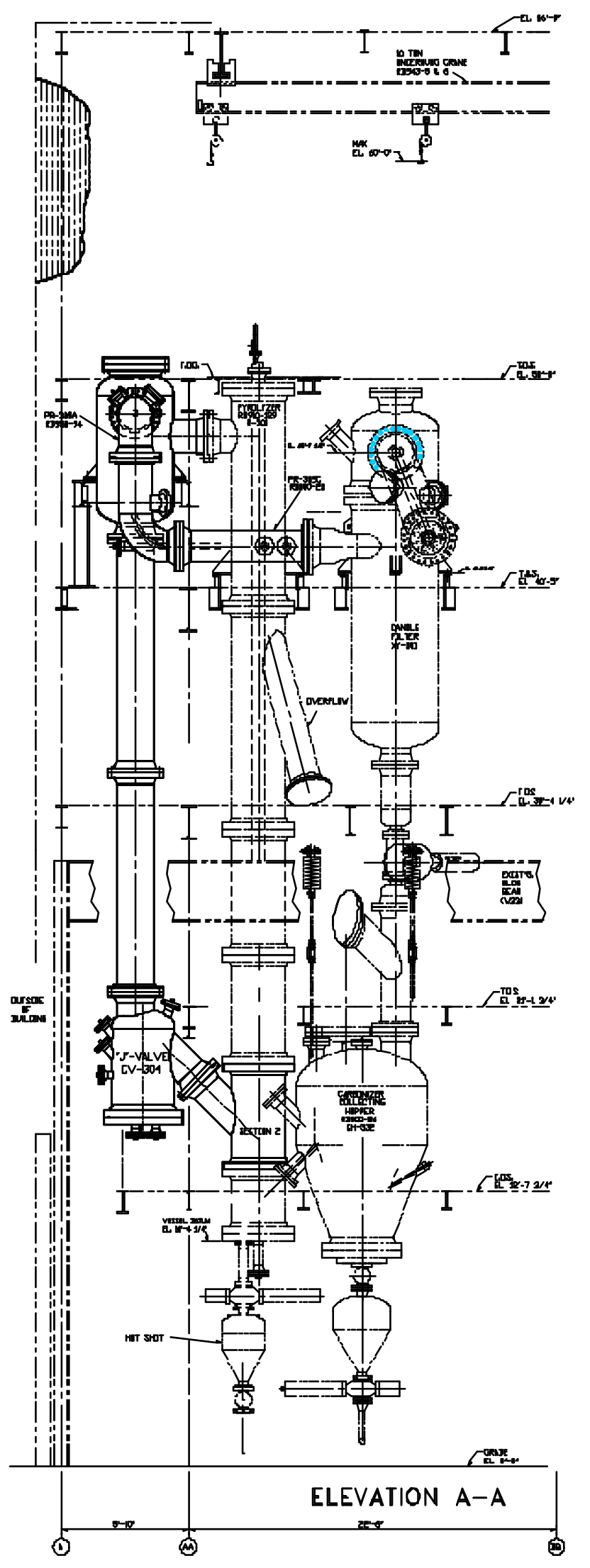

Figure 4 CFB Pyrolyzer General Arrangement 


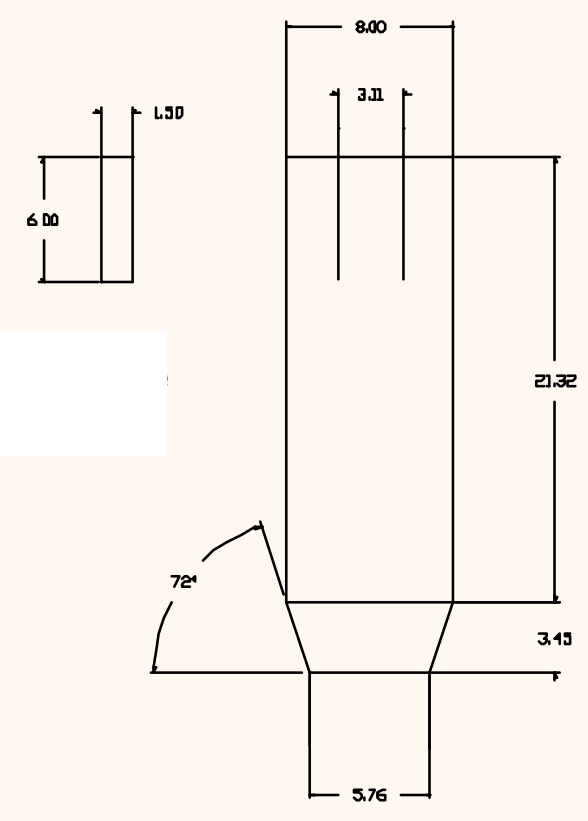

All units in inches unless othermise noted. All Dimensions are Internal Dims

Figure 5 New Cyclone Design

\section{Task 4 - Subsystem Test Unit Construction}

\section{Subtask - 4.1 Livingston Pilot Plant Construction}

During this quarter, the demolition work of the existing bubbling-bed pyrolyzer is complete. The preliminary construction work of the CFB pyrolyzer has been underway. The following parts of the existing pyrolyzer will be modified or added:

- Pyrolyzer refractory modification

- Back end control valve:

- $\quad$ Fixed flow orifice modification

- Bypass syngas cooler addition

- Recirculation loop arrangement:

- New cyclone and J-valve addition

- Structural steel modification

- Instrumentation specification and addition

- Sampling probes:

- Mass spectrum reinstallation

- Trace metal probe design and fabrication 
- Flame Arrestors :

- New flame arrestor procurement and replacement

\section{- Feed System:}

- A side-feed port addition

The overall construction and testing schedule for the CFB pyrolyzer test is shown in Figure 6. Due to several key personnel changes related to this project during this quarter, the original planned test schedule has been delayed by approximately six months. As shown in Figure 6, HIPPS testing on the circulating fluidized bed pyrolyzer can begin as early as November 2000.

\section{Subtask - 4.2 Char Combustion System Construction}

In our previous burner tests at our Combustion and Environmental Test Facility (CETF) in Dansville, NY, an indirect feed system was employed to deliver char to the burner in the arch-fired configuration. This system did not perform as originally specified by the vendor, and the fuel flow to the burner was unstable. The modifications to the existing indirect feed system are needed to improve both system performance and accuracy. A process schematic of the CETF for the new wall-fired configuration is presented in Figure 7. The new design of the char silo and indirect feed system is shown in Figure 8. The new feed system is a loss-in-weight and pneumatic conveying feed system. During this quarter, we completed the modification and construction work of the new feed system. Figure 9 shows the picture of the new complete silo and feed system. Figure 10 shows the picture of the new loss-in-weight feeder.

\section{Task 5 - Subsystem Test Unit Testing}

No experimental testing was performed during this quarter 


\begin{tabular}{|c|c|c|c|c|c|c|c|c|c|c|c|c|c|c|c|}
\hline \multirow[b]{2}{*}{ ID } & \multirow[b]{2}{*}{ Task Name } & \multicolumn{6}{|c|}{2000} & \multicolumn{8}{|c|}{2001} \\
\hline & & \begin{tabular}{|l|l|} 
Apr & May \\
\end{tabular} & \begin{tabular}{|l|} 
Jun \\
\end{tabular} & \begin{tabular}{l|l} 
Jul & Aug \\
\end{tabular} & \begin{tabular}{|l|l|} 
Sep & Oct \\
\end{tabular} & Nov & Dec & Jan & Feb & Mar & Apr & May & Juח & Jul & Aug \\
\hline 1 & CFB Pyrolyzer Test & & & & & & & & & & & & & & \\
\hline 2 & Demolition & 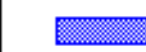 & & & & & & & & & & & & & \\
\hline 3 & Design and Engineering & 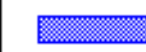 & m & & & & & & & & & & & & \\
\hline 4 & Preliminary Construction & & $=$ & 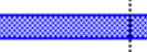 & & & & & & & & & & & \\
\hline 5 & Procurement & & & & 7 & & & & & & & & & & \\
\hline 6 & Plant Construction & & & & & & & & & & & & & & \\
\hline 7 & Shakedown Test & & & & & & & & & & & & & & \\
\hline 8 & Testing - Series I & & & & & & & & & & & & & & \\
\hline 9 & Testing - Series II & & & & & & & & & & & & & & \\
\hline 10 & Data Analysis and Reporting & & & & & & & & & & & & & & \\
\hline
\end{tabular}

Figure 6 Overall CFB Pyrolyzer System Construction and Testing Schedule 


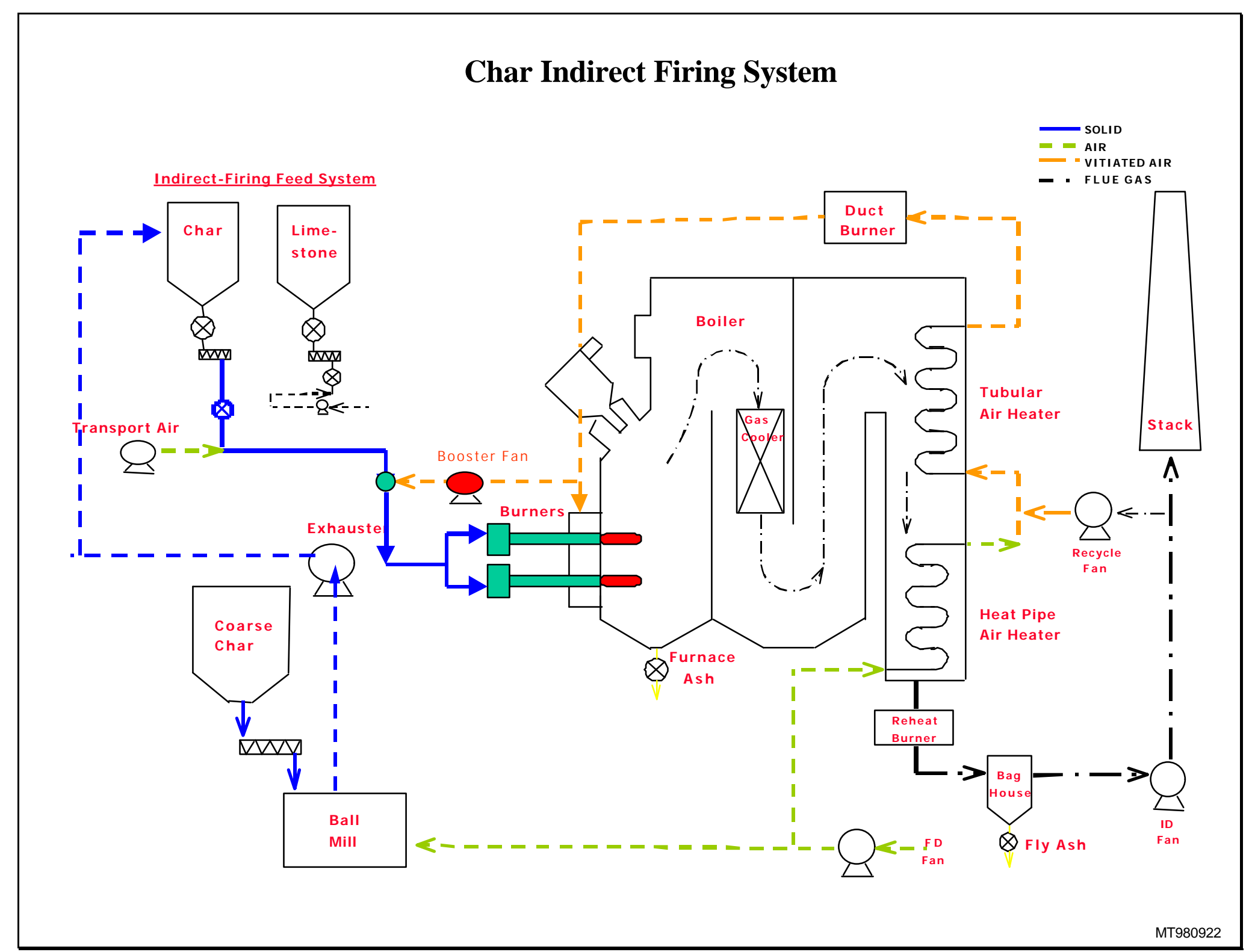

Figure 7 CETF Process Schematic 


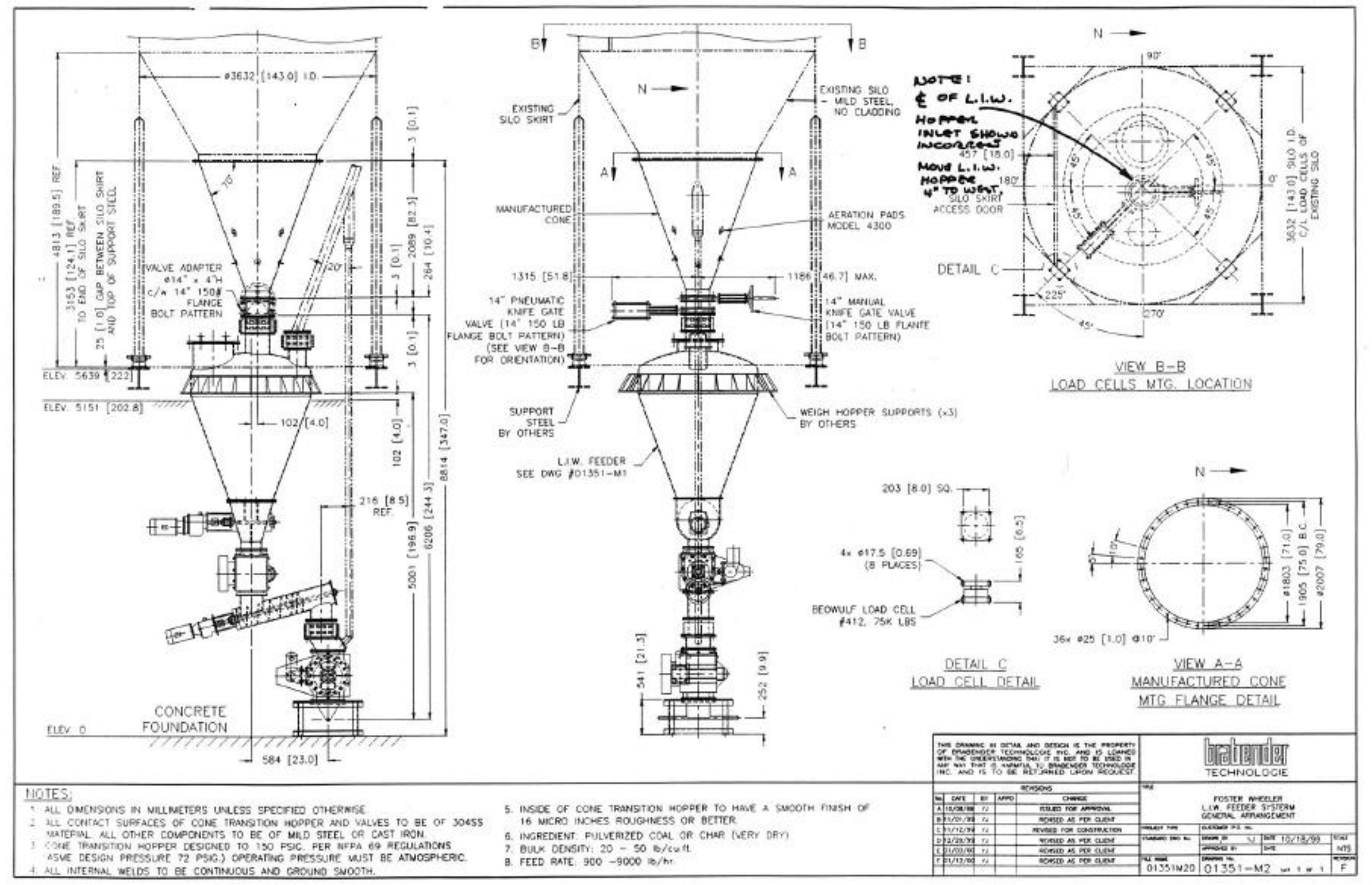

Figure 8 New Loss-in-Weight and Pneumatic Conveying Feed System 


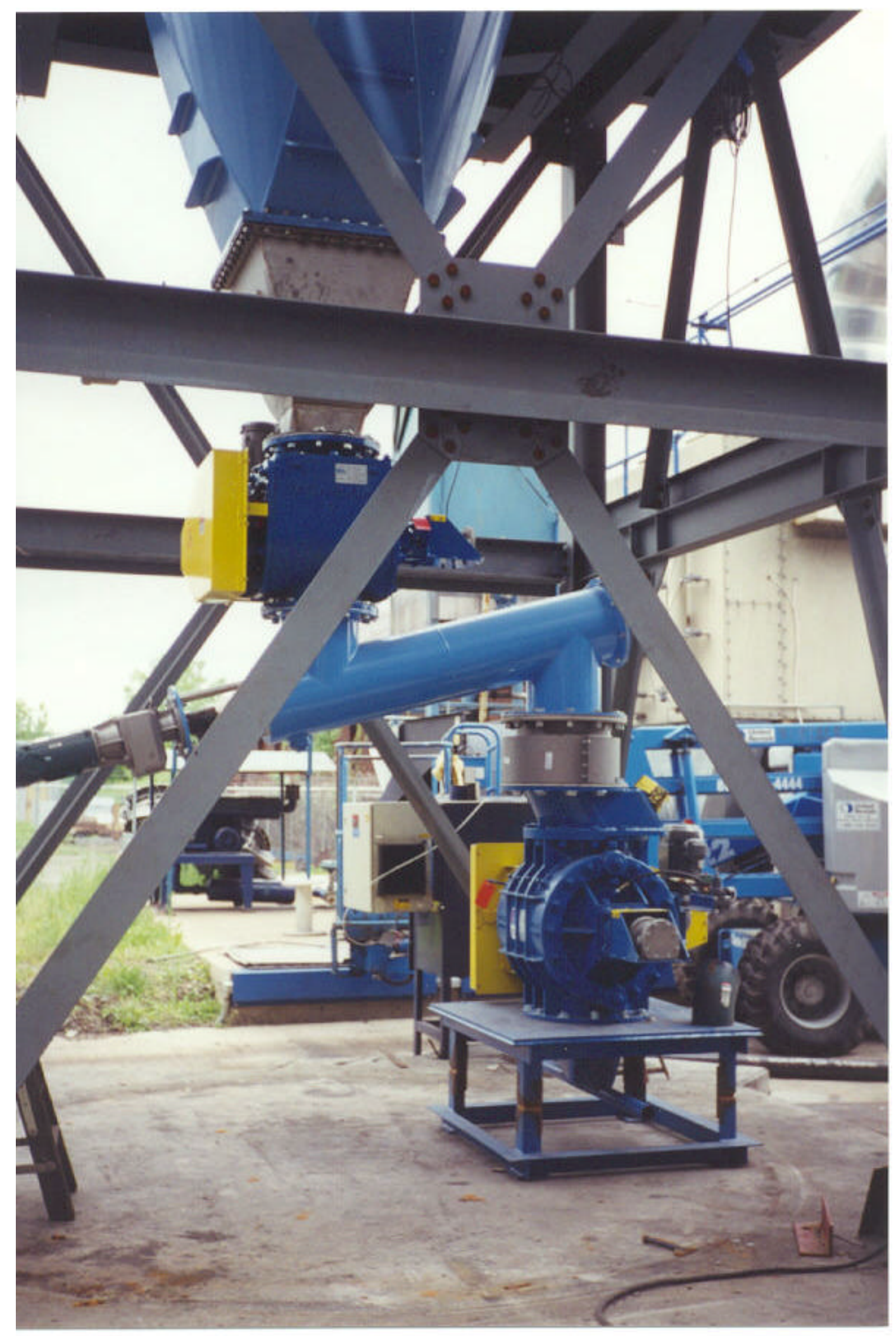

Figure 9 Picture of the New Indirect Feed System 


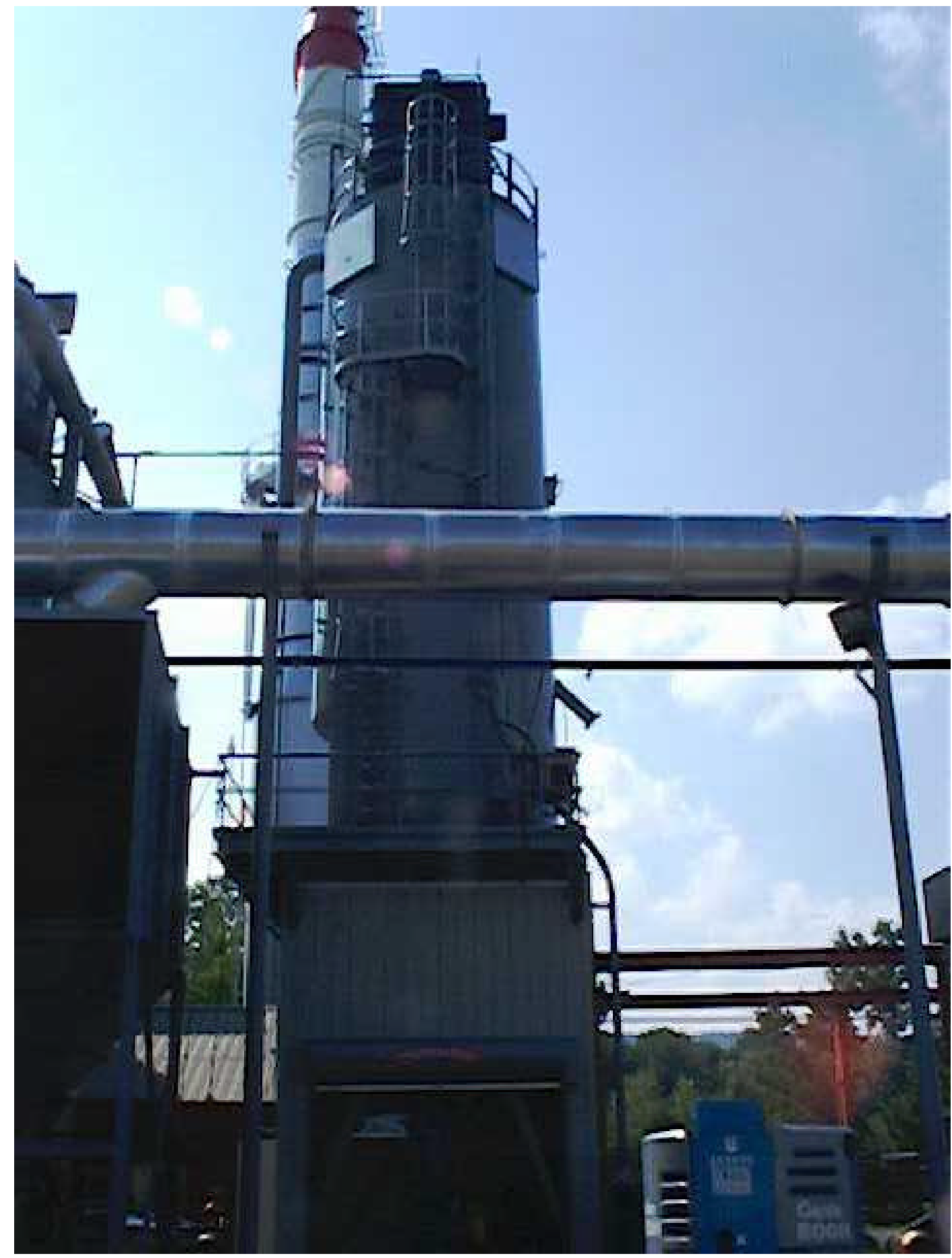

Figure 10 Picture of the New Loss-in-Weight Feed System 